\title{
Genomic Grade Index predicts postoperative clinical outcome of GIST
}

\author{
F Bertucci ${ }^{*}, 1,2,3$, P Finetti', J Ostrowski ${ }^{4}$, WK Kim ${ }^{5}$, H Kim $^{5}$, MA Pantaleo ${ }^{6}$, A Astolfi', M Polkowski ${ }^{8}$ and \\ D Birnbaum'
}

'Department of Molecular Oncology, Centre de Recherche en Cancérologie de Marseille; UMRI068 Inserm; Institut Paoli-Calmettes, 232 Boulevard Sainte Marguerite, 13273 Marseille Cedex 09, France; ' ${ }^{2}$ epartment of Medical Oncology, Institut Paoli-Calmettes, Centre de Recherche en Cancérologie de Marseille, UMR 068 Inserm, Marseille, France; ${ }^{3}$ Aix-Marseille University, Marseille, France; ${ }^{4}$ Department of Oncological Genetics, M Sklodowska-Curie Memorial Cancer Center and Institute of Oncology, Warsaw, Poland; ${ }^{5}$ Department of Pathology, Yonsei University College of Medicine, Seoul, Korea; ${ }^{6}$ Department of Hematology and Oncological Sciences, L.A. Seragnoli, S. Orsola-Malpighi Hospital, University of Bologna, Bologna, Italy; ${ }^{7}$ Interdepartmental Centre for Cancer Research G. Prodi, University of Bologna, Bologna, Italy; ${ }^{8}$ Department of Gastroenterology, Medical Center of Postgraduate Education, Warsaw, Poland

BACKGROUND: Prognosis of localised gastrointestinal stromal tumour (GIST) is heterogeneous, notably for patients with AFIP intermediate or high risk of relapse, who are candidates to adjuvant imatinib. We hypothesised that gene expression profiles might improve the prognostication and help to refine the indications for imatinib.

METHODS: We collected gene expression and histoclinical data of 146 pre-treatment localised GIST samples treated with surgery alone. We searched for a gene expression signature (GES) predictive for relapse-free survival (RFS) and compared its performances to that of three published prognostic proliferation-based GES (Genomic Grade Index (GGI), I6-Kinase, and CINSARC) and AFIP classification. We also analysed a data set from 28 patients with advanced GIST treated with neo-adjuvant imatinib.

RESULTS: We identified a 275-gene GES (gene expression signature) predictive of RFS in a learning set and validated its robustness in an independent set. However, the GGl outperformed its prognostic performances, and those of the two other signatures and the AFIP intermediate-risk classification in two independent tests sets in uni- and multivariate analyses. Importantly, GGl could split the AFIP intermediate/high-risk samples into two groups with different RFS. Genomic Grade Index 'high-risk' tumours were more proliferative and genetically unstable than 'low-risk' tumours, and more sensitive to imatinib.

CONCLUSION: GGI refines the prediction of RFS in localised GIST and might help tailor adjuvant imatinib.

British Journal of Cancer (2012) I 07, |433-144I. doi: I0.1038/bjc.20 I2.390 www.bjcancer.com

Published online 28 August 2012

(c) 2012 Cancer Research UK

Keywords: DNA microarray; gene expression; GIST; imatinib; profiling; prognosis

Gastrointestinal stromal tumours (GISTs) are the most frequent mesenchymal digestive tumours (Kitamura et al, 2003; Corless et al, 2011). Characterised by activating KIT or PDGFRA mutations, which rend them sensitive to tyrosine kinase inhibitors (imatinib and sunitinib), they represent a model for molecularbased diagnosis (West et al, 2004) and treatment (Antonescu, 2011; Joensuu and Dematteo, 2012). The mainstay of treatment for localised tumour is complete surgical resection (Casali and Blay, 2010). However, the postoperative clinical outcome is heterogeneous, and $20-40 \%$ of patients will relapse. KIT and PDGFRA mutations are early molecular events in GIST development, but those that accumulate during the disease progression are poorly elucidated. The current prognostic criteria - anatomical site, pathological tumour size, mitotic count and tumour rupture (Dematteo et al, 2008; Casali and Blay, 2010) - are combined in several risk classifications: NIH 2002 (Fletcher et al, 2002), AFIP 2007 (Miettinen and Lasota, 2006), and Joensuu's classification (Joensuu, 2008). Based on recent studies (Dematteo et al, 2009;

\footnotetext{
*Correspondence: Professor F Bertucci;

E-mail: BERTUCCIF@ipc.unicancer.fr

Received 7 June 2012; revised 20 July 2012; accepted 6 August 2012; published online 28 August 2012
}

Joensuu et al, 2011), adjuvant imatinib is recommended for patients with 'substantial risk of relapse' according to ESMO guidelines and with 'intermediate to high risk' according to AFIP. In Europe, the AFIP classification is widely used. However, the 2-year relapse-free survival (RFS) without adjuvant imatinib is close to $75 \%$ in the AFIP intermediate-risk patients and $50 \%$ in the high-risk patients (Dematteo et al, 2009), meaning that many of them are in fact cured by surgery alone.

Today, the imperfection of these risk stratification systems imposes to refine them to better tailor adjuvant treatment (Patel, 2011). The knowledge of molecular alterations may help achieve this. Prognostic value has been associated with the type of KIT/ PDGFRA mutation (Heinrich et al, 2008a, b) and with a few markers (Schneider-Stock et al, 2005; Sabah et al, 2006; Schmieder et al, 2008). But the results are still in some cases contradictory, and these alterations, not currently considered as established independent prognostic factors, are not included in risk classifications. High-throughput gene expression profiling may improve the prognostic classification of cancers, as observed in breast cancer (Bertucci et al, 2006). Several DNA microarray-based studies of GIST samples (Allander et al, 2001; Antonescu et al, 2004; Koon et al, 2004; Subramanian et al, 2004; Kang et al, 2005; Yamaguchi et al, 2008; Ostrowski et al, 2009; Rink et al, 2009; Astolfi et al, 
2010; Yang et al, 2010; Arne et al, 2011; Ylipaa et al, 2011; Lagarde et al, 2012) have highlighted the transcriptional heterogeneity of the disease, notably related to the location, the mutational status, and the risk group. But these series are relatively small (60 cases for the largest one), only 4 directly addressed the prognostic issue (Koon et al, 2004; Yamaguchi et al, 2008; Arne et al, 2011; Lagarde et al, 2012), and none identified a multigene predictor that was tested in an independent validation set.

Here, we analysed expression data of 146 imatinib-untreated localised GIST profiled using whole-genome DNA microarrays, and searched for a GES predictive for RFS after surgery.

\section{MATERIALS AND METHODS}

\section{Tumour samples}

We collected from our databases (Kang et al, 2005; Ostrowski et al, 2009; Astolfi et al, 2010) and public databases (Yamaguchi et al, 2008; Rink et al, 2009; Lagarde et al, 2012) clinical and wholegenome expression data of pre-treatment samples from 146 non-metastatic GIST patients (Kang et al, 2005; Yamaguchi et al, 2008; Ostrowski et al, 2009; Astolfi et al, 2010; Lagarde et al, 2012) treated with complete primary surgery without adjuvant imatinib (Table 1), and from 28 patients with advanced GIST treated with neo-adjuvant imatinib in the Radiation Therapy Oncology Group Study 0132 (RTOG0132; Rink et al, 2009). Data sets are described

Table I Histoclinical characteristics of the I46 GIST samples

\begin{tabular}{|c|c|}
\hline Characteristics $(N)$ & $\mathbf{N}(\%)$ \\
\hline \multicolumn{2}{|l|}{$\operatorname{Sex}(146)$} \\
\hline F & $56(38)$ \\
\hline M & $90(62)$ \\
\hline \multicolumn{2}{|l|}{ Age (86) } \\
\hline$\leqslant 60$ & $38(44)$ \\
\hline$>60$ & $48(56)$ \\
\hline \multicolumn{2}{|l|}{ Site (146) } \\
\hline G & $116(79)$ \\
\hline $\mathrm{SI}$ & $21(14)$ \\
\hline Other & $9(7)$ \\
\hline \multicolumn{2}{|l|}{ Size (86) } \\
\hline$\leqslant 5$ & $36(42)$ \\
\hline$\leqslant 10$ & $32(37)$ \\
\hline$>10$ & $18(21)$ \\
\hline \multicolumn{2}{|l|}{$\operatorname{AFIP}(146)$} \\
\hline Low & $77(53)$ \\
\hline Intermediate & $30(21)$ \\
\hline High & $39(27)$ \\
\hline \multicolumn{2}{|l|}{ Mutation (145) } \\
\hline KIT_ex9 & $9(6)$ \\
\hline KIT_exII & $93(64)$ \\
\hline KIT_exI3 & $1(1)$ \\
\hline KIT_exI7 & I (I) \\
\hline PDGFRA_ex 12 & $5(3)$ \\
\hline PDGFRA_ex|4 & I (I) \\
\hline PDGFRA_ex 18 & $18(12)$ \\
\hline Wild type & $17(12)$ \\
\hline \multicolumn{2}{|l|}{ Relapse (146) } \\
\hline 0 & | 14 (78) \\
\hline । & $32(22)$ \\
\hline 5 Year RFS (86) & $79 \%(0.69-0.90)$ \\
\hline Median follow-up, months (range) & $47(2-165)$ \\
\hline
\end{tabular}

Abbreviations: ex=exon; $F=$ female; $G=$ gastric; $G I S T=$ gastrointestinal stroma tumour; $M=$ male; $R F S=$ relapse-free survival; $S I=$ small intestine. in Supplementary Table S1. Samples were profiled using wholegenome DNA microarrays: Affymetrix U133 Plus 2.0 (Yamaguchi et al, 2008; Ostrowski et al, 2009; Astolfi et al, 2010), Agilent 44K (Rink et al, 2009; Lagarde et al, 2012), and home-made microarrays spotted at the Genome Institute of Singapore (Kang et al, 2005). The study was approved by our Institutional Board.

\section{Gene expression data analysis}

Before analysis, we first re-annotated all hybridisation probes present on the three types of microarrays (Affymetrix, Agilent, and Singapore's microarrays). Affymetrix gene chips annotations were updated using NetAffx Annotation files (www.affymetrix.com; release from 1 December 2008). Agilent gene chips annotations were retrieved and updated using both SOURCE (http://smd. stanford.edu/cgi-bin/source/sourceSearch) and EntrezGene (Homo sapiens gene information database, release from 09 December 2008, ftp://ftp.ncbi.nlm.nih.gov/gene/). Regarding the Singapore chips, the 18664 probe sets representing 18664 unique (LEADSt) genes were updated using both SOURCE and EntrezGene. All probes were thus mapped based on their EntrezGeneID. When multiple probes were mapped to the same GeneID, the one with the highest variance in a particular data set was selected to represent the GeneID.

Data sets were then processed as follows. For the Agilent-based sets and the Singapore set, we used the available processed data. Regarding the Affymetrix-based data sets, we applied Robust Multichip Average to the raw data before using distance weighted discrimination to make each set comparable to each other using the Yamaguchi's set as reference. Robust Multichip Average was done in R using Bioconductor (Seattle, WA, USA) and associated packages.

Unsupervised hierarchical clustering was applied to Affymetrix data only. Before clustering, a filtering retained the 12619 genes with the most variable expression across all samples (s.d. $\geqslant 0.25$ ). Clustering was done with the Cluster program (Eisen et al, 1998) using Pearson's uncentered correlation and centroid linkage clustering. Results were displayed using TreeView program (Eisen et al, 1998). Biologically relevant gene clusters were identified and summarised as metagenes for prognostic analysis. Metagene expression value was the mean of the normalised expression values of all genes in the respective gene subset. Once computed, the metagenes were tested as continuous value for their prognostic incidence with respect to RFS using Cox regression univariate and multivariate analyses.

Supervised analysis searched for a GES associated with RFS. The data set was split into a learning set (64 Affymetrix samples; Yamaguchi et al, 2008; Ostrowski et al, 2009; Astolfi et al, 2010) and a validation set (82 independent, non-Affymetrix samples; Kang et al, 2005; Rink et al, 2009; Lagarde et al, 2012). Cox regression analysis (Wald test) was applied to the 17870 genes using a FDR threshold of $1 \%$ after adjustment for testing of multiple hypotheses. The robustness of the signature was then tested in the independent validation set: by classifying samples according to the Pearson correlation coefficient of their expression profile with the mean profile of the samples with relapse from the learning set. The resulting gene list was interrogated using the Ingenuity Pathway Analysis (IPA) software (Redwood City, CA, USA) to assess significant representation of biological pathways (thresholds of significance for $P$-values were 0.001 ).

We also tested the prognostic value of three proliferation-based GES previously reported in breast cancer and soft tissue sarcoma: the Genomic Grade Index (GGI), which includes 128 probe sets (108 genes; Sotiriou et al, 2006), the 16-kinase signature (16-Kinase), which includes 16 kinase genes (Finetti et al, 2008), and the CINSARC signature, which includes 67 genes (Chibon et al, 2010). Each signature was applied in each of the five data sets separately to guarantee the largest number of common genes as 
possible. We then strictly applied the same method (score or correlation, cutoffs, and scaling methods) as that reported in the original publications to classify each sample into the prognostic group 'low-risk' or 'high-risk'. More details are available in Supplementary Table S2. Another supervised analysis comparing the gene expression profiles of the two GGI-based sample groups was done in the Affymetrix data set using significance analysis of microarrays with a FDR threshold of $1 \%$.

\section{Statistical analyses}

Correlations between sample groups and histoclinical factors were calculated with the Fisher's exact test for qualitative variables and the Mann-Whitney test for continuous variables. The primary endpoint was RFS calculated from the date of diagnosis until date of first relapse whatever its location using the Kaplan-Meier method. In one data set (Lagarde et al, 2012), the presence or absence of relapse was documented without information about the delay (60 samples). In the whole data set $(N=146), 114$ patients did not experience any relapse, whereas 32 relapsed. In the 86 cases with available time information, the median follow-up - measured from the date of diagnosis to the date of last news - was 47 months (range, 2-165) for the 71 relapse-free patients; the median time to relapse was 19 months (range, 5-74) for the 15 patients who relapsed, and the 5-year RFS was 79\% (CI 95\% (69-90)). Survival was compared between groups with the log-rank test. Univariate and multivariate analyses were done using either Cox regression analysis when the time information was available, or a logistic regression analysis using the $\mathrm{glm}$ function (R's statistical package) when it was not available (significance estimated by specifying a binomial family for model with a logit link). The variables tested in univariate analyses included the sample classification based on each GES 'high-risk' vs 'low-risk' and the AFIP classification (high $v s$ intermediate $v s$ low-risk). Multivariate analysis incorporated all variables with a $P$-value inferior to $1 \%$ in univariate analysis. The Cox multivariate analysis was done with the Cox proportional hazard model or Cox regression with the Firth's correction ( $\mathrm{R}$ software, Bioconductor) depending on occurrence or not of relapse in the reference group. All statistical tests were two-sided at the $5 \%$ level of significance. Statistical analysis was done using the survival package (version 2.30) in the $\mathrm{R}$ software (version 2.9.1). The paper is written in accordance with reporting recommendations for tumour marker prognostic studies (REMARK) criteria (McShane et al, 2005).

\section{RESULTS}

\section{Whole-genome gene expression profiles}

Hierarchical clustering was applied to 64 samples and 12619 most varying genes in the Affymetrix data set (Supplementary Figure S1). As reflected by the dendrogram, the samples displayed heterogeneous expression profiles (Supplementary Figures S1A and B). They were sorted into two main 32 sample clusters (I and II), which correlated with the anatomical site (69\% gastric in cluster I vs $100 \%$ in cluster II, $P=8.5 \mathrm{E}-04)$ and the mutation status (84\% KIT-mutated in cluster II vs $48 \%$ in cluster I, and 3\% PDGFRA-mutated in cluster II vs $29 \%$ in cluster I, $P=3.2 \mathrm{E}-04)$. No significant correlation existed with the AFIP classification or clinical outcome, even if cluster II included more AFIP high-risk patients $(34 \%$ vs $15 \%$ in cluster I; $P=0.17)$, and more patients with relapse during follow-up (22\% vs $9 \%$; $P=0.3 ; \mathrm{HR}=2.67$ ).

Several gene clusters were evidenced. Some of them defined expression signatures related to specific cell types, biological functions, or chromosomal locations (Supplementary Figures $\mathrm{S} 1 \mathrm{~A}-\mathrm{C})$. A proliferation cluster included two classical proliferation markers (MKI67 and PCNA) and many genes involved in the cell cycle and mitosis such as $A U R K A / B$; cyclin genes, TOP2A, TTK, or $B U B 1$. Visually, this cluster was more expressed in AFIP high-risk samples in agreement with a likely higher mitotic index. An immune cluster reflected variation in specific immune cell types within the tumours. It included genes encoding markers of B cells (immunoglobulins and HLA molecules), T cells (CD3, ZAP70, and CD4), NK cells (NKG7 and CD244), or macrophages (CD68, CD14, and CSF1R). Visually, this cluster was more expressed in PDGFRA-mutated samples in agreement with their classically high lymphocyte infiltrate (Subramanian et al, 2004). An early response gene cluster, including for example FOS, ATF3, DUSP2, and NR4A2, appeared more expressed in PDGFRA-mutated samples as expected (Subramanian et al, 2004). A cluster, enriched in genes involved in angiogenesis (VEGFA, TEK, FLT1/3, CDH5, and PECAM1) was overall overexpressed in samples without KIT exon 11 mutation as expected (Imamura et al, 2007). Finally, a cluster of co-expressed genes represented a presumptive lost chromosomal region (9p loss cluster, of which $15 \%$ of genes are located on the $9 p$ chromosomal arm); its expression was visually negatively correlated with that of the 'proliferation cluster' and associated with worse RFS as previously reported (Schneider-Stock et al, 2005; Haller et al, 2008a). We tested the prognostic value of these five clusters computed as metagenes. The proliferation, $9 p$ loss, and early response metagenes were associated with poor RFS in Cox univariate analysis $(P<0.05$, Wald test), whereas the two other ones (immune and vascular) were not. In multivariate analysis including the three significant metagenes, only the proliferation metagene remained significant.

We also confirmed the overexpression of some individual control genes in relation with the mutation status (Subramanian et al, 2004; Chi et al, 2010; Arne et al, 2011): KIT, CD34, ETV1, PROM1 (CD133), or RPS6KA1 in KIT-mutated samples, EPHA4 or DSG2 for KIT exon 9 mutations, and PDGFRA, IGFBP5, IGF1, SPON1, or PRKCA for PDGFRA mutations.

\section{GES for RFS}

We searched for a GES associated with RFS. The data set was split into a learning set and a validation set. To avoid additional normalisation, we used the Affymetrix set as learning set $(N=64)$ and the two other sets as independent validation set $(N=82)$. In the learning set (10 relapses), Cox analysis identified 275 discriminating genes (FDR 1\%; Supplementary Table S3), including 129 genes overexpressed and 146 underexpressed in samples with event. As expected, the resulting classification of learning set samples strongly correlated with clinical outcome $(P=8.5 \mathrm{E}-04$, Supplementary Figure S2A). More importantly, in the validation set (Supplementary Figure S2B), 39 out of 60 (65\%) patients who did not relapse were classified by the signature as 'low-risk', and 21 out of $22(95 \%)$ patients who relapsed were accurately predicted as 'high-risk'. The rate of accurate classification was $73 \%$, suggesting the robustness of the signature $(P=5.4 \mathrm{E}-07)$. When applied to the whole series of samples (learning and validation sets pooled), 71 out of $114(63 \%)$ patients who did not relapse were classified as 'low-risk', and 31 out of 32 (97\%) patients who relapsed were accurately predicted as 'high-risk' $(P=3.7 \mathrm{E}-10)$. Considering the 86 patients with available RFS time, the 5 -year RFS was $97 \%$ (CI $95 \%(92-100))$ in the 'low-risk' group $(N=39)$ and $64 \%(C I 95 \%$ $(50-84))$ in the 'high-risk' group $(N=47)$ as defined using the signature $(P=0.0016$, Figure $1 \mathrm{~A})$.

The biological significance of the signature was interrogated using the IPA gene ontology software (Supplementary Table S4A). No significantly enriched canonical pathway was identified for the 146 underexpressed genes. By contrast, analysis found a significant overrepresentation of cell cycle-associated pathways within the overexpressed genes. 
A 275-Gene signature

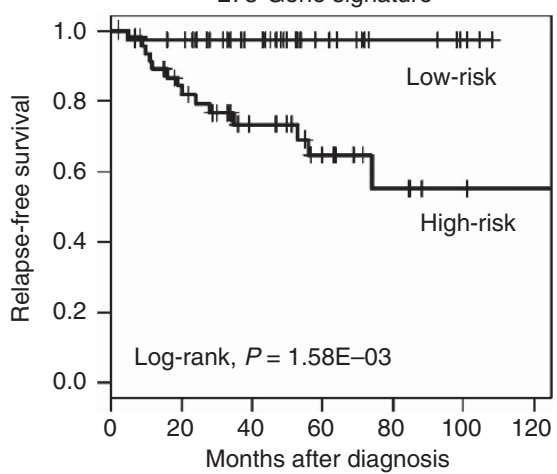

C

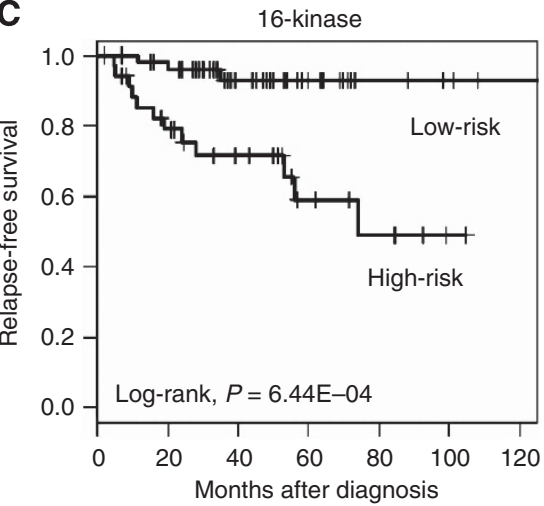

B

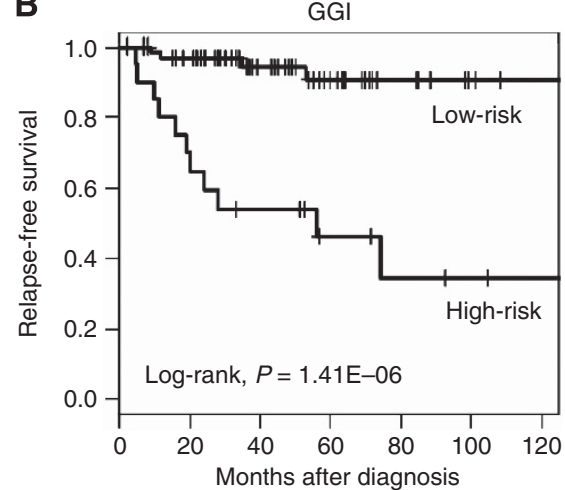

D

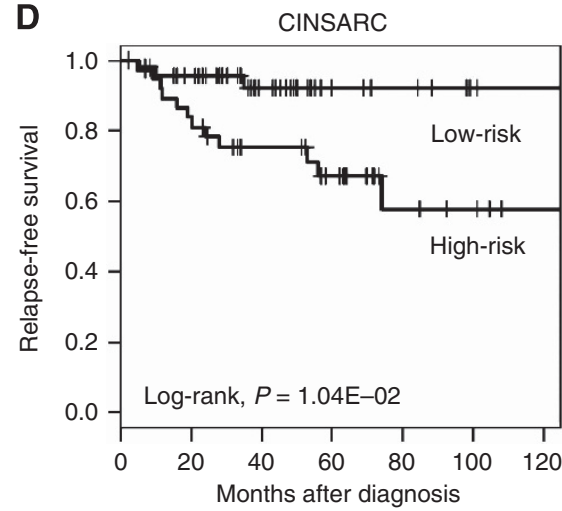

Figure I Time-dependent correlation between the classifications based on four prognostic GES and RFS in 86 GIST samples. Kaplan-Meier RFS curves of the two GIST groups (low-risk and high-risk) defined by the: (A) 275-gene signature, (B) GGl, (C) I6-Kinase signature, and (D) CINSARC.

Table 2 Correlation between the classifications based on three prognostic GES and RFS in GIST samples in the two tests sets, separately and pooled

\begin{tabular}{|c|c|c|c|c|c|c|c|c|c|c|c|c|}
\hline \multirow{2}{*}{$\begin{array}{l}\text { Prognostic } \\
\text { GES }\end{array}$} & \multicolumn{3}{|c|}{ Relapse } & \multirow{2}{*}{$\begin{array}{c}P \text {-value }{ }^{a} \\
\text { OR }(95 \% \mathrm{Cl})\end{array}$} & \multicolumn{3}{|c|}{ Relapse } & \multirow{2}{*}{$\begin{array}{c}P \text {-value }{ }^{\text {a }} \\
\text { OR }(95 \% \mathrm{Cl})\end{array}$} & \multicolumn{3}{|c|}{ Relapse } & \multirow{2}{*}{$\begin{array}{c}\text { P-value }{ }^{\text {a }} \\
\text { OR }(95 \% \mathrm{Cl})\end{array}$} \\
\hline & No & Yes & Total & & No & Yes & Total & & No & Yes & Total & \\
\hline \multicolumn{13}{|l|}{ GGl } \\
\hline \multicolumn{13}{|l|}{ 16-Kinase } \\
\hline Low-risk & 48 & 3 & 51 & $1.04 \mathrm{E}-03$ & 33 & । & 34 & $4.75 E-07$ & 81 & 4 & 85 & $3.77 E-09$ \\
\hline High-risk & 23 & 12 & 35 & $8.1(1.9-49.3)$ & 10 & 16 & 26 & $48.75(6.2-2246.3)$ & 33 & 28 & 61 & | $6.8(5.3-7 \mid .1)$ \\
\hline \multicolumn{13}{|l|}{ CINSARC } \\
\hline Low-risk & 45 & 3 & 48 & $3.34 \mathrm{E}-03$ & 32 & 0 & 32 & $5.54 \mathrm{E}-08$ & 77 & 3 & 80 & $2.30 E-09$ \\
\hline
\end{tabular}

Abbreviations: $\mathrm{Cl}=$ confidence interval; CINSARC = complexity index in sarcomas; GES = gene expression signature; GGI = Genomic Grade Index; GIST= gastrointestinal

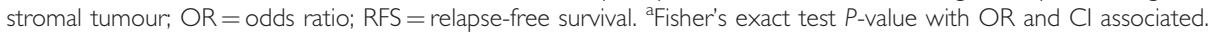

\section{Prognostic value of three proliferation-based GES}

Given the importance of proliferation genes in this signature, we tested whether three published proliferation-associated GES with prognostic value in breast cancer (GGI, 16-Kinase signature) and sarcomas (CINSARC) had prognostic value in GISTs. Analysis was done in two separated test sets (no. 1 and no. 2). We first analysed the 86 sample series (test set no. 1) where the time to RFS was available. Each GES divided samples into two groups 'low-risk' and 'high-risk' with different 5-year RFS (Figures 1B-D), respectively, 91\% (CI 95\% (82-100); $N=66)$ and 46\% (CI 95\% (28-77); $N=20)$ with the GGI $(P=1.4 \mathrm{E}-06), 93 \%(\mathrm{CI} 95 \%(85-100) ; N=51)$ and $59 \%$ (CI 95\% (42-84); $N=35$ ) with the 16-Kinase signature $(P=6.44 \mathrm{E}-04)$, and $92 \%(\mathrm{CI} 95 \%(84-100) ; N=48)$ and $67 \%$ (CI 95\% (53-86); $N=38)$ with CINSARC $(P=0.01)$. Table 2 shows the corresponding contingency tables. Although each signature gave significant results, the largest difference in RFS was observed with the GGI. 
Table 3 Univariate and multivariate analyses for RFS

\begin{tabular}{|c|c|c|c|c|c|c|}
\hline \multirow[b]{2}{*}{ Test set no. I ( $N=86$; time to RFS available) } & \multicolumn{3}{|c|}{$\begin{array}{l}\text { Univariate: } \\
\text { Cox regression }\end{array}$} & \multicolumn{3}{|c|}{$\begin{array}{l}\text { Multivariate: Cox regression using } \\
\text { Firth's bias reduction }\end{array}$} \\
\hline & $\mathbf{N}$ & HR (95\% Cl) & $P$-value & $\mathbf{N}$ & HR $(95 \% \mathrm{Cl})$ & $P$-value \\
\hline \multicolumn{7}{|l|}{ GGI } \\
\hline \multicolumn{7}{|l|}{ AFIP } \\
\hline $\begin{array}{l}\text { Intermediate vs low } \\
\text { High vs low }\end{array}$ & $\begin{array}{l}86 \\
86\end{array}$ & $\begin{array}{l}3.84 E 08(0-\ln f) \\
2.17 E 09(0-\operatorname{lnf})\end{array}$ & $3.38 \mathrm{E}-08$ & $\begin{array}{l}86 \\
86\end{array}$ & $\begin{array}{l}11.2(0.87-1.6 \mathrm{E} 03) \\
44.1(5.23-5.8 \mathrm{E} 03)\end{array}$ & $\begin{array}{l}0.06 \\
3.01 \mathrm{E}-05\end{array}$ \\
\hline \multicolumn{7}{|l|}{ 275-gene } \\
\hline Poor vs good & \multicolumn{3}{|c|}{ Univariate: logistic regression } & \multicolumn{3}{|c|}{ Multivariate: logistic regression } \\
\hline Test set no. 2 ( $N=60$; time to RFS not available) & $\mathbf{N}$ & Coefficient & $P$-value & $\mathbf{N}$ & Coefficient & $P$-value \\
\hline \multicolumn{7}{|l|}{ GGl } \\
\hline \multicolumn{7}{|l|}{ AFIP } \\
\hline Intermediate vs low & 60 & 0.29 & $9.17 \mathrm{E}-03$ & 60 & 0.11 & 0.19 \\
\hline High vs low & 60 & 0.78 & $8.13 E-11$ & 60 & 0.41 & $5.83 E-05$ \\
\hline \multicolumn{7}{|l|}{ 275-gene } \\
\hline \multirow[t]{2}{*}{ Poor vs good } & 60 & 0.63 & $1.22 E-09$ & 60 & 0.27 & $7.14 \mathrm{E}-04$ \\
\hline & \multicolumn{3}{|c|}{ Univariate: logistic regression } & \multicolumn{3}{|c|}{ Multivariate: logistic regression } \\
\hline Pooled test sets $(N=146$; all samples) & $\mathbf{N}$ & Coefficient & $P$-value & $\mathbf{N}$ & Coefficient & $P$-value \\
\hline \multicolumn{7}{|l|}{ GGl } \\
\hline \multicolumn{6}{|l|}{ AFIP } & $1.25 E-07$ \\
\hline Intermediate vs low & 146 & 0.20 & $<2.00 E-16$ & 146 & 0.12 & 0.05 \\
\hline High vs low & 146 & 0.67 & $8.13 \mathrm{E}-11$ & 146 & 0.42 & $1.75 E-10$ \\
\hline \multicolumn{7}{|l|}{ 275-gene } \\
\hline Poor vs good & 146 & 0.41 & $3.62 E-10$ & 146 & 0.15 & $2.88 \mathrm{E}-03$ \\
\hline
\end{tabular}

Abbreviations: $\mathrm{Cl}=$ confidence interval; $\mathrm{GGI}=$ Genomic Grade Index; HR = hazard ratio; RFS = relapse-free survival.

For further validation in an independent set, we repeated the analysis in the 60 Lagarde's samples. In this series, the time to relapse was not available (test set no. 2). The correlation between the resulting classification and the survival was thus analysed using contingency tables (Table 2). Correlation was significant for each signature, but again stronger for the GGI. When we pooled the two test sets $(N=146)$, the rate of accurate classifications was $88 \%$ for GGI, $75 \%$ for the 16 -Kinase signature, and $73 \%$ for CINSARC (Table 2). We thus focused on the GGI in the next sections.

\section{Univariate and multivariate analyses for RFS}

We compared the prognostic performances of the classifications based on the 275-gene GES, GGI, and AFIP (Table 3). Analysis was done in the two test sets, separately then pooled.

In the test set no. 1 (86 samples with available time to RFS) Cox univariate analysis confirmed the prognostic value of the three classifiers. In multivariate analysis, the GGI and the AFIP high-risk classification remained significant, suggesting their independent prognostic value, but the AFIP intermediate-risk classification was not. Genomic Grade Index sorted the AFIP intermediate/high-risk samples into two groups 'low-risk' and 'high-risk' with respective 5 -year RFS of 73\% (CI 95\% (52-100); $N=22$ ) and 35\% (CI 95\% $(17-70) ; N=16 ; P=8.5 \mathrm{E}-03$; Figure 2).

As independent validation, we repeated the analyses in the test set no. 2 (Lagarde's 60 sample series) using logistic regression. Results of univariate analysis were similar. In multivariate analysis, the GGI signature remained significant, whereas the AFIP

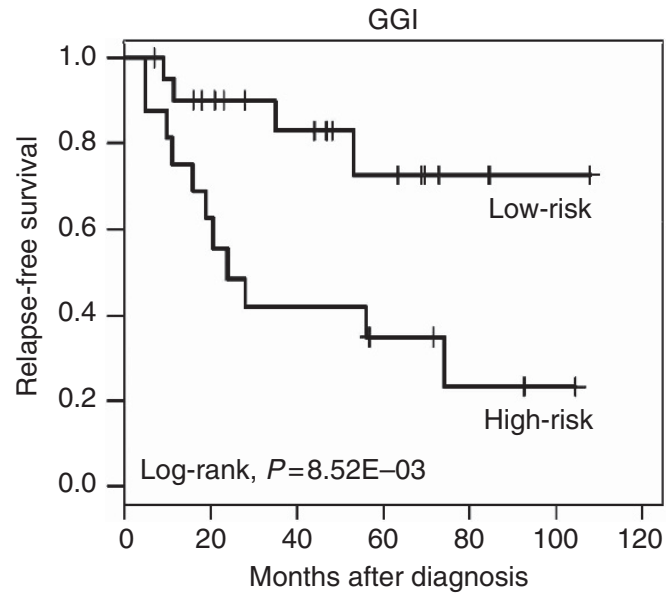

Figure 2 Correlation between the GGl-based classification and RFS in the AFIP intermediate/high-risk GIST samples. Kaplan-Meier RFS curves in the patients with available RFS time $(N=38)$.

intermediate-risk classification was not. Genomic Grade Index sorted the AFIP intermediate/high-risk samples into two groups with different relapse rate: 4 out of 17 patients (24\%) in the 'low-risk' group and 13 out of 14 (93\%) in the 'high-risk' $(\mathrm{OR}=35.7 ; P=1.8 \mathrm{E}-04)$. When we pooled the two test sets $(N=146)$, similar results were observed (Table 3$)$. 


\section{Comparison of the two GGI-based GIST groups}

The GGI was thus an independent predictor for RFS in two independent GIST tests sets. To explore the differences between the so-defined GGI 'low-risk' and 'high-risk' groups, we compared their histoclinical features $(N=146$; Supplementary Table S5). Significant differences existed for three parameters. Genomic Grade Index 'high-risk' samples were more frequently AFIP highrisk $(P=1.0 \mathrm{E}-05)$ and superior to $10 \mathrm{~cm}(P=1.22 \mathrm{E}-04)$, and displayed more relapses $(P=3.6 \mathrm{E}-13$ : $\mathrm{OR}=29.84)$ despite a similar follow-up. The AFIP intermediate/high-risk samples were sorted by GGI into two groups with different rate of relapses: 8 out of 39 patients $(21 \%)$ in the 'low-risk' group and 24 out of $30(80 \%)$ in the 'high-risk' group ( $\mathrm{OR}=14.7 ; P=8.8 \mathrm{E}-07)$.

We then compared the whole-genome expression profiles of the two groups in the Affymetrix 64 sample series. Significance analysis of microarrays analysis identified 254 discriminating genes (FDR 1\%), including 192 genes overexpressed and 62 underexpressed in the 'high-risk' samples (Supplementary Table S6). Ontology analysis found an overrepresentation of canonical pathways within the overexpressed genes only (Supplementary Table S4B). Most of them were associated with cell cycle control and genome stability: examples include 'mitotic roles of polo-like kinase', 'role of chk proteins in cell cycle checkpoint control', 'cell cycle: G2/M DNA damage checkpoint regulation', or 'cell cycle control of chromosomal replication'. Of note, 10 out of the 16 significant pathways $(62.5 \%)$ were common to those identified by IPA analysis of the genes overexpressed in the 275-gene GES.

\section{GGI-based classification and response to imatinib}

A major and complementary issue is to determine whether the GGI 'high-risk' patients are more sensitive to imatinib. We analysed a set of 28 pre-treatment samples from patients with advanced primary and recurrent operable GIST treated in a phase II trial (RTOG0132) with 8-12 weeks neo-adjuvant imatinib and for whom the degree of clinical response (RECIST by comparing tumour measurements on computed tomography scans before and after imatinib) was available (Rink et al, 2009). The percentage of tumour shrinkage ranged from -76 to $+21 \%$.

We reproduced the two GGI-based groups. As expected given the advanced stage of disease, more patients were classified as 'high-risk' $(N=24)$ than 'low-risk' $(N=4)$. Despite the low number of samples, the correlation between those groups and the degree of response (continuous variable) was significant with greater tumour shrinkage in the 'high-risk' group than the 'lowrisk' group (mean $-29 \%$ vs $-5 \%, P=0.04$; Figure 3 ). By applying the response definition used in the original paper (binary variable), the correlation was high, even if not significant owing to the number of cases: 17 out of 24 'high-risk' samples (71\%) were classified as rapid responders, whereas 3 out of 4 'low-risk' samples $(75 \%)$ as non-responders $(P=0.116)$, with a OR for response of 6.7 in the 'high-risk' group as compared with the 'lowrisk' group. These results suggested that GGI 'high-risk' patients are more imatinib sensitive than are 'low-risk' patients.

\section{DISCUSSION}

The risk of postoperative relapse in GIST patients dictates the delivery or not of adjuvant imatinib and the follow-up. Risk stratification systems based on histoclinical features exist, but are not perfect to solve the actual prognostic heterogeneity of disease. In Europe, the current gold standard is the AFIP classification and all intermediate- or high-risk patients are candidate to imatinib although many of them are in fact cured by surgery alone and do not need any postoperative therapy. Better identifying them would avoid not only the imatinib-related toxicity, but also the financial cost related to at least 1-3 years of treatment. Efforts are ongoing

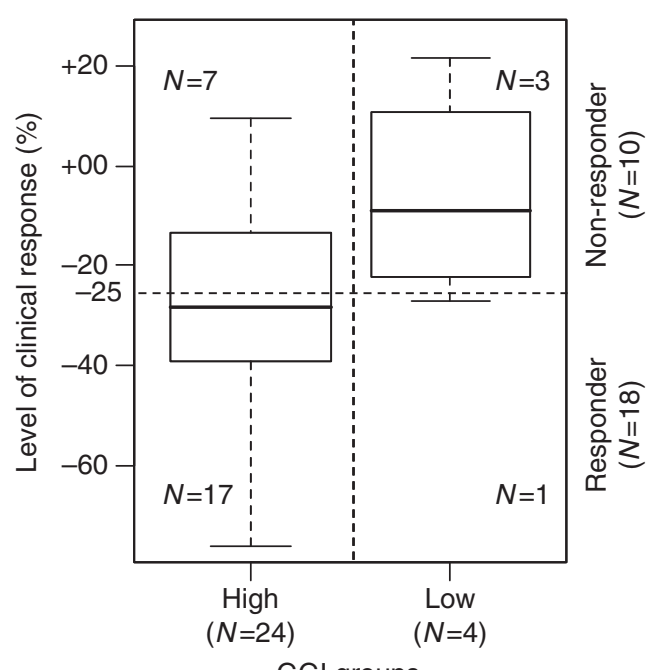

GGI groups

Figure 3 Correlation between the GGl-based classification and the response to neo-adjuvant imatinib. Correlation between the two GGl-based groups (high-risk and low-risk; $N=29$ ) and the response to imatinib assessed as a continuous variable (box plot). The horizontal dashed line indicates the cutoff of tumour shrinkage that defines the responder status. The figures within the box plot indicate the number of patients in each of the four categories.

to improve these stratification systems (Gold et al, 2009; Patel, 2011; Rossi et al, 2011; Joensuu et al, 2012). Although GIST is the most frequent digestive sarcoma, it has been only recently defined as an entity and the research on DNA microarrays and GIST prognosis has suffered from a lack of large clinically documented series (60 cases for the largest one), impeding the use of independent learning and validation sets. We analysed gene expression and histoclinical data of 146 localised GIST operated and untreated with adjuvant imatinib to assess the prognostic performance of gene expression profiles. To our knowledge, this is the largest series reported to date, and the first one that includes independent validation.

Unsupervised analysis confirmed the transcriptional heterogeneity of disease and expression differences associated with the mutation status. Supervised analysis searched for a GES associated with RFS. As recommended, our data set was split into two sets, learning and validation sets. We identified a 275-gene GES associated with RFS in a learning set and validated its robustness in an independent validation set. As this GES was mainly driven by proliferation genes, we hypothesised that three robust prognostic signatures associated with cell cycle control might be predictive for RFS in GIST. These signatures had been identified using hypothesis-driven approaches in breast cancer (by comparing histological grade III $v s$ I for GGI, and basal $v s$ luminal subtype for the 16-Kinase) and in sarcoma (CINSARC by comparing samples with high $v s$ low number of genomic alterations and high $v s$ low histological grade). Of note, none of the GIST samples had been used to generate these signatures. However, we divided our data set in two independent test sets, and interestingly, each signature had a prognostic value in each set. As GGI was the most significant one, we compared its prognostic performances with those of the 275-gene GES and the AFIP classification. We found that GGI and the AFIP high-risk classification were independent prognosticators in both test sets. Genomic Grade Index provided additional information to AFIP by discriminating within the intermediate/ high-risk AFIP patients those with good prognosis GGI 'low-risk', who are not likely to need adjuvant imatinib, from those with poor prognosis GGI 'high-risk', who likely need imatinib. 
Interestingly, we showed in a series of patients treated with neo-adjuvant imatinib for primary GIST (Rink et al, 2009) that GGI 'high-risk' patients were more frequently rapid responders to imatinib than 'low-risk' patients. If confirmed in a larger series, this correlation would further increase the clinical interest of GGI in GIST.

Ontologies associated with the genes discriminating the two GGI-based groups showed that the poor prognosis of 'high-risk' group was mainly related to alterations in cell cycle control and maintenance of genome stability, these tumours being more proliferative and more unstable at the chromosomal level. This was confirmed using GSEA and a GES of genome instability (Carter et al, 2006; normalised enrichment score $=1.86$, $P<2.12 \mathrm{E}-16$; data not shown). This higher instability likely confers to 'high-risk' tumours the ability to accumulate molecular alterations allowing them to metastasise. The prognostic importance of proliferation in GIST is well known. The mitotic index is a component of current risk stratifications systems, but is liable to interobserver and technical variability (Patel, 2011). The prognostic value of expression of cell cycle-regulatory genes has been reported (Haller et al, 2005; Schneider-Stock et al, 2005; Sabah et al, 2006; Schmieder et al, 2008; Haller et al, 2008a, b; Romeo et al, 2009; Dorn et al, 2010; Fujita et al, 2012; Okamoto et al, 2012). To date, four studies have analysed the prognostic value of gene expression profiles (Koon et al, 2004; Yamaguchi et al, 2008; Arne et al, 2011; Lagarde et al, 2012), but the largest one included 60 cases only. Here, using a stringent significance threshold and in our 146 sample series, CCNB1 and CENPF (Koon et al, 2004) were included in our 275-gene list, but CD133 (Arne et al, 2011) and CD26 (Yamaguchi et al, 2008) were not; however, CD26 expression was associated with RFS $(P=0.0085)$ using less stringent criteria. Recently, Lagarde et al (2012) showed the prognostic value of CINSARC and AURKA expression, and developed a Genomic Index defined upon array-CGH data as a score of genomic instability associated with metastasis-free survival. Unfortunately, this prognosticator was not validated by the authors in an independent sample set. Here, we confirmed the prognostic value of CINSARC, but showed that GGI was a stronger prognosticator in two independent test sets.

Several genes included in the GGI and/or overexpressed in the GGI 'high-risk' samples encode potential therapeutic targets involved in cell cycle regulation that could be, if functionally validated, targeted by new drugs in the adjuvant setting, alone or associated with imatinib: kinases $(A U R K A / B, B U B 1, C D C 2, C D K 4$, CHEK1, NEK2, and PLK1/4) and phosphatase (CDC25). Corresponding inhibitors have entered cancer clinical trials with promising results.

In conclusion, we show that a GGI-based classification of operated GIST outperforms the prognostic performances of three other GES and the AFIP intermediate-risk classification. The strength of our results lies in the size of our series (the largest one reported so far), the biological relevance of GGI, its independent prognostic value in two independent test sets through three different technological platforms. Of note, GGI sorts the AFIP intermediate/high-risk samples - current candidate to adjuvant imatinib - into two groups with different RFS. 'High-risk' tumours according to GGI are more proliferative and genetically unstable than 'low-risk' tumours, and more rapidly sensitive to imatinib. By refining the prediction of RFS, GGI might improve our ability to better tailor adjuvant imatinib. Further clinical validation of GGI is warranted in larger retrospective, then prospective series, as well as the functional validation of relevant genes that could provide new therapeutical targets.

\section{ACKNOWLEDGEMENTS}

This work is supported by the Institut Paoli-Calmettes, Inserm, Institut National du Cancer ( $\operatorname{Tr} 2008$ ), Ligue Nationale contre le Cancer (label DB), and Comité de Corse du Sud de la Ligue Nationale contre le Cancer.

Supplementary Information accompanies the paper on British Journal of Cancer website (http://www.nature.com/bjc)

\section{REFERENCES}

Allander SV, Nupponen NN, Ringner M, Hostetter G, Maher GW, Goldberger N, Chen Y, Carpten J, Elkahloun AG, Meltzer PS (2001) Gastrointestinal stromal tumors with KIT mutations exhibit a remarkably homogeneous gene expression profile. Cancer Res 61: 8624-8628

Antonescu CR (2011) The GIST paradigm: lessons for other kinase-driven cancers. J Pathol 223: 251-261

Antonescu CR, Viale A, Sarran L, Tschernyavsky SJ, Gonen M, Segal NH, Maki RG, Socci ND, DeMatteo RP, Besmer P (2004) Gene expression in gastrointestinal stromal tumors is distinguished by KIT genotype and anatomic site. Clin Cancer Res 10: 3282-3290

Arne G, Kristiansson E, Nerman O, Kindblom LG, Ahlman H, Nilsson B, Nilsson O (2011) Expression profiling of GIST: CD133 is associated with KIT exon 11 mutations, gastric location and poor prognosis. Int J Cancer 129: 1149-1161

Astolfi A, Nannini M, Pantaleo MA, Di Battista M, Heinrich MC, Santini D, Catena F, Corless CL, Maleddu A, Saponara M, Lolli C, Di Scioscio V, Formica S, Biasco G (2010) A molecular portrait of gastrointestinal stromal tumors: an integrative analysis of gene expression profiling and high-resolution genomic copy number. Lab Invest 90: 1285-1294

Bertucci F, Finetti P, Cervera N, Maraninchi D, Viens P, Birnbaum D (2006) Gene expression profiling and clinical outcome in breast cancer. Omics 10: 429-443

Carter SL, Eklund AC, Kohane IS, Harris LN, Szallasi Z (2006) A signature of chromosomal instability inferred from gene expression profiles predicts clinical outcome in multiple human cancers. Nat Genet 38: 1043-1048

Casali PG, Blay JY (2010) Gastrointestinal stromal tumours: ESMO Clinical Practice Guidelines for diagnosis, treatment and follow-up. Ann Oncol 21(Suppl 5): v98-102
Chi P, Chen Y, Zhang L, Guo X, Wongvipat J, Shamu T, Fletcher JA, Dewell S, Maki RG, Zheng D, Antonescu CR, Allis CD, Sawyers CL (2010) ETV1 is a lineage survival factor that cooperates with KIT in gastrointestinal stromal tumours. Nature 467: 849-853

Chibon F, Lagarde P, Salas S, Perot G, Brouste V, Tirode F, Lucchesi C, de Reynies A, Kauffmann A, Bui B, Terrier P, Bonvalot S, Le Cesne A, Vince-Ranchere D, Blay JY, Collin F, Guillou L, Leroux A, Coindre JM, Aurias A (2010) Validated prediction of clinical outcome in sarcomas and multiple types of cancer on the basis of a gene expression signature related to genome complexity. Nat Med 16: 781-787

Corless CL, Barnett CM, Heinrich MC (2011) Gastrointestinal stromal tumours: origin and molecular oncology. Nat Rev Cancer 11: $865-878$

Dematteo RP, Ballman KV, Antonescu CR, Maki RG, Pisters PW, Demetri GD, Blackstein ME, Blanke CD, von Mehren M, Brennan MF, Patel S, McCarter MD, Polikoff JA, Tan BR, Owzar K (2009) Adjuvant imatinib mesylate after resection of localised, primary gastrointestinal stromal tumour: a randomised, double-blind, placebo-controlled trial. Lancet 373: 1097-1104

Dematteo RP, Gold JS, Saran L, Gonen M, Liau KH, Maki RG, Singer S, Besmer P, Brennan MF, Antonescu CR (2008) Tumor mitotic rate, size, and location independently predict recurrence after resection of primary gastrointestinal stromal tumor (GIST). Cancer 112: 608-615

Dorn J, Spatz H, Schmieder M, Barth TF, Blatz A, Henne-Bruns D, Knippschild U, Kramer K (2010) Cyclin H expression is increased in GIST with very-high risk of malignancy. BMC Cancer 10: 350

Eisen MB, Spellman PT, Brown PO, Botstein D (1998) Cluster analysis and display of genome-wide expression patterns. Proc Natl Acad Sci USA 95: 14863-14868 
Finetti P, Cervera N, Charafe-Jauffret E, Chabannon C, Charpin C, Chaffanet M, Jacquemier J, Viens P, Birnbaum D, Bertucci F (2008) Sixteen-kinase gene expression identifies luminal breast cancers with poor prognosis. Cancer Res 68: 767-776

Fletcher CD, Berman JJ, Corless C, Gorstein F, Lasota J, Longley BJ, Miettinen M, O'Leary TJ, Remotti H, Rubin BP, Shmookler B, Sobin LH, Weiss SW (2002) Diagnosis of gastrointestinal stromal tumors: a consensus approach. Hum Pathol 33: 459-465

Fujita A, Yamamoto H, Imamura M, Nakamura N, Maehara Y, Tsuneyoshi M, Oda Y (2012) Expression level of the mitotic checkpoint protein and G2-M cell cycle regulators and prognosis in gastrointestinal stromal tumors in the stomach. Virchows Arch 460: 163-169

Gold JS, Gonen M, Gutierrez A, Broto JM, Garcia-del-Muro X, Smyrk TC, Maki RG, Singer S, Brennan MF, Antonescu CR, Donohue JH, DeMatteo RP (2009) Development and validation of a prognostic nomogram for recurrence-free survival after complete surgical resection of localised primary gastrointestinal stromal tumour: a retrospective analysis. Lancet Oncol 10: 1045-1052

Haller F, Gunawan B, von Heydebreck A, Schwager S, Schulten HJ, Wolf-Salgo J, Langer C, Ramadori G, Sultmann H, Fuzesi L (2005) Prognostic role of E2F1 and members of the CDKN2A network in gastrointestinal stromal tumors. Clin Cancer Res 11: 6589-6597

Haller F, Lobke C, Ruschhaupt M, Cameron S, Schulten HJ, Schwager S, von Heydebreck A, Gunawan B, Langer C, Ramadori G, Sultmann H, Poustka A, Korf U, Fuzesi L (2008a) Loss of 9p leads to p16INK4A down-regulation and enables RB/E2F1-dependent cell cycle promotion in gastrointestinal stromal tumours (GISTs). J Pathol 215: 253-262

Haller F, Lobke C, Ruschhaupt M, Schulten HJ, Schwager S, Gunawan B, Armbrust T, Langer C, Ramadori G, Sultmann H, Poustka A, Korf U, Fuzesi L (2008b) Increased KIT signalling with up-regulation of cyclin D correlates to accelerated proliferation and shorter disease-free survival in gastrointestinal stromal tumours (GISTs) with KIT exon 11 deletions. J Pathol 216: 225-235

Heinrich MC, Maki RG, Corless CL, Antonescu CR, Harlow A, Griffith D, Town A, McKinley A, Ou WB, Fletcher JA, Fletcher CD, Huang X, Cohen DP, Baum CM, Demetri GD (2008a) Primary and secondary kinase genotypes correlate with the biological and clinical activity of sunitinib in imatinib-resistant gastrointestinal stromal tumor. J Clin Oncol 26: 5352-5359

Heinrich MC, Owzar K, Corless CL, Hollis D, Borden EC, Fletcher CD, Ryan CW, von Mehren M, Blanke CD, Rankin C, Benjamin RS, Bramwell VH, Demetri GD, Bertagnolli MM, Fletcher JA (2008b) Correlation of kinase genotype and clinical outcome in the North American Intergroup Phase III Trial of imatinib mesylate for treatment of advanced gastrointestinal stromal tumor: CALGB 150105 Study by Cancer and Leukemia Group B and Southwest Oncology Group. J Clin Oncol 26: 5360-5367

Imamura $\mathrm{M}$, Yamamoto $\mathrm{H}$, Nakamura $\mathrm{N}$, Oda $\mathrm{Y}$, Yao $\mathrm{T}$, Kakeji $\mathrm{Y}$ Baba H, Maehara Y, Tsuneyoshi M (2007) Prognostic significance of angiogenesis in gastrointestinal stromal tumor. Mod Pathol 20: 529-537

Joensuu H (2008) Risk stratification of patients diagnosed with gastrointestinal stromal tumor. Hum Pathol 39: 1411-1419

Joensuu H, Dematteo RP (2012) The management of gastrointestinal stromal tumors: a model for targeted and multidisciplinary therapy of malignancy. Annu Rev Med 63: 247-258

Joensuu H, Eriksson M, Hatrmann J, Sundby Hall K, Schutte J, Reichardt A, Schlemmer M, Wardelmann E, Ramadori G, Al-Batran S, Nilsson BE Monge $\mathrm{O}$, Kallio $\mathrm{R}$, Sarlomo-Rikala $\mathrm{M}$, Bono $\mathrm{P}$, Leinonen $\mathrm{M}$, Hohenberger P, Alvegard T, Reichardt P (2011) Twelve versus 36 months of adjuvant imatinib (IM) as treatment of operable GIST with a high risk of recurrence: final results of a randomized trial (SSGXVIII/AIO). J Clin Oncol 29, (suppl; abstr LBA1)

Joensuu H, Vehtari A, Riihimaki J, Nishida T, Steigen SE, Brabec P Plank L, Nilsson B, Cirilli C, Braconi C, Bordoni A, Magnusson MK, Linke Z, Sufliarsky J, Federico M, Jonasson JG, Dei Tos AP, Rutkowski P (2012) Risk of recurrence of gastrointestinal stromal tumour after surgery: an analysis of pooled population-based cohorts. Lancet Oncol 13: $265-274$

Kang HJ, Nam SW, Kim H, Rhee H, Kim NG, Kim H, Hyung WJ, Noh SH, Kim JH, Yun CO, Liu ET, Kim H (2005) Correlation of KIT and platelet-derived growth factor receptor alpha mutations with gene activation and expression profiles in gastrointestinal stromal tumors. Oncogene 24: 1066-1074
Kitamura Y, Hirota S, Nishida T (2003) Gastrointestinal stromal tumors (GIST): a model for molecule-based diagnosis and treatment of solid tumors. Cancer Sci 94: 315-320

Koon N, Schneider-Stock R, Sarlomo-Rikala M, Lasota J, Smolkin M, Petroni G, Zaika A, Boltze C, Meyer F, Andersson L, Knuutila S, Miettinen M, El-Rifai W (2004) Molecular targets for tumour progression in gastrointestinal stromal tumours. Gut 53: 235-240

Lagarde P, Perot G, Kauffmann A, Brulard C, Dapremont V, Hostein I, Neuville A, Wozniak A, Sciot R, Schoffski P, Aurias A, Coindre JM, Debiec-Rychter M, Chibon F (2012) Mitotic checkpoints and chromosome instability are strong predictors of clinical outcome in gastrointestinal stromal tumors. Clin Cancer Res 18: 826-838

McShane LM, Altman DG, Sauerbrei W, Taube SE, Gion M, Clark GM (2005) Reporting recommendations for tumor marker prognostic studies. J Clin Oncol 23: 9067-9072

Miettinen M, Lasota J (2006) Gastrointestinal stromal tumors: pathology and prognosis at different sites. Semin Diagn Pathol 23: 70-83

Okamoto Y, Sawaki A, Ito S, Nishida T, Takahashi T, Toyota M, Suzuki H, Shinomura Y, Takeuchi I, Shinjo K, An B, Ito H, Yamao K, Fujii M, Murakami H, Osada H, Kataoka H, Joh T, Sekido Y, Kondo Y (2012) Aberrant DNA methylation associated with aggressiveness of gastrointestinal stromal tumour. Gut 61: 392-401

Ostrowski J, Polkowski M, Paziewska A, Skrzypczak M, Goryca K, Rubel T, Kokoszynska K, Rutkowski P, Nowecki ZI, Vel Dobosz AJ, Jarosz D, Ruka W, Wyrwicz LS (2009) Functional features of gene expression profiles differentiating gastrointestinal stromal tumours according to KIT mutations and expression. BMC Cancer 9: 413

Patel S (2011) Navigating risk stratification systems for the management of patients with GIST. Ann Surg Oncol 18: 1698-1704

Rink L, Skorobogatko Y, Kossenkov AV, Belinsky MG, Pajak T, Heinrich MC, Blanke CD, von Mehren M, Ochs MF, Eisenberg B, Godwin AK (2009) Gene expression signatures and response to imatinib mesylate in gastrointestinal stromal tumor. Mol Cancer Ther 8: $2172-2182$

Romeo S, Debiec-Rychter M, Van Glabbeke M, Van Paassen H, Comite P, Van Eijk R, Oosting J, Verweij J, Terrier P, Schneider U, Sciot R, Blay JY, Hogendoorn PC (2009) Cell cycle/apoptosis molecule expression correlates with imatinib response in patients with advanced gastrointestinal stromal tumors. Clin Cancer Res 15: 4191-4198

Rossi S, Miceli R, Messerini L, Bearzi I, Mazzoleni G, Capella C, Arrigoni G, Sonzogni A, Sidoni A, Toffolatti L, Laurino L, Mariani L, Vinaccia V, Gnocchi C, Gronchi A, Casali PG, Dei Tos AP (2011) Natural history of imatinib-naive GISTs: a retrospective analysis of 929 cases with longterm follow-up and development of a survival nomogram based on mitotic index and size as continuous variables. Am J Surg Pathol 35: $1646-1656$

Sabah M, Cummins R, Leader M, Kay E (2006) Altered expression of cell cycle regulatory proteins in gastrointestinal stromal tumors: markers with potential prognostic implications. Hum Pathol 37: 648-655

Schmieder M, Wolf S, Danner B, Stoehr S, Juchems MS, Wuerl P, Henne-Bruns D, Knippschild U, Hasel C, Kramer K (2008) p16 expression differentiates high-risk gastrointestinal stromal tumor and predicts poor outcome. Neoplasia 10: 1154-1162

Schneider-Stock R, Boltze C, Lasota J, Peters B, Corless CL, Ruemmele P, Terracciano L, Pross $M$, Insabato $L$, Di Vizio $D$, Iesalnieks $I$, Dirnhofer S, Hartmann A, Heinrich M, Miettinen M, Roessner A, Tornillo L (2005) Loss of p16 protein defines high-risk patients with gastrointestinal stromal tumors: a tissue microarray study. Clin Cancer Res 11: 638-645

Sotiriou C, Wirapati P, Loi S, Harris A, Fox S, Smeds J, Nordgren $\mathrm{H}$, Farmer P, Praz V, Haibe-Kains B, Desmedt C, Larsimont D, Cardoso F, Peterse H, Nuyten D, Buyse M, Van de Vijver MJ, Bergh J, Piccart M, Delorenzi M (2006) Gene expression profiling in breast cancer: understanding the molecular basis of histologic grade to improve prognosis. J Natl Cancer Inst 98: 262-272

Subramanian S, West RB, Corless CL, Ou W, Rubin BP, Chu KM, Leung SY, Yuen ST, Zhu S, Hernandez-Boussard T, Montgomery K, Nielsen TO, Pate RM, Goldblum JR, Heinrich MC, Fletcher JA, van de Rijn M (2004) Gastrointestinal stromal tumors (GISTs) with KIT and PDGFRA mutations have distinct gene expression profiles. Oncogene 23: 7780-7790

West RB, Corless CL, Chen X, Rubin BP, Subramanian S, Montgomery K, Zhu S, Ball CA, Nielsen TO, Patel R, Goldblum JR, Brown PO, Heinrich MC, van de Rijn M (2004) The novel marker, DOG1, is expressed ubiquitously in gastrointestinal stromal tumors irrespective of KIT or PDGFRA mutation status. Am J Pathol 165: 107-113 
Yamaguchi U, Nakayama R, Honda K, Ichikawa H, Hasegawa T, Shitashige M, Ono M, Shoji A, Sakuma T, Kuwabara H, Shimada Y, Sasako M, Shimoda T, Kawai A, Hirohashi S, Yamada T (2008) Distinct gene expression-defined classes of gastrointestinal stromal tumor. J Clin Oncol 26: 4100-4108

Yang D, Ylipaa A, Yang J, Hunt K, Pollock R, Trent J, Yli-Harja O, Shmulevich I, Nykter M, Zhang W (2010) An integrated study of aberrant gene copy number and gene expression in GIST and LMS. Technol Cancer Res Treat 9: 171-178

Ylipaa A, Hunt KK, Yang J, Lazar AJ, Torres KE, Lev DC, Nykter M, Pollock RE, Trent J, Zhang W (2011) Integrative genomic characterization and a genomic staging system for gastrointestinal stromal tumours. Cancer 117: 380-389

This work is published under the standard license to publish agreement. After 12 months the work will become freely available and the license terms will switch to a Creative Commons Attribution-NonCommercial-Share Alike 3.0 Unported License. 